\title{
Securing Methods, Practicing Critique: A Review of Methods and Critical Security Studies
}

\author{
Review by LaURen Wilcox \\ University of Cambridge, Centre for Gender Studies
}

Laura J. Shepherd, ed. (2013). Critical Approaches to Security: An Introduction to Theories and Methods. Routledge, London and New York, 304 pp., \$160.00 hardcover (ISBN-13 978-0-41568017-2), \$54.95 paperback (ISBN-13 978-0-415-68016-5).

Mark B. Salter and Can E. Mutlu, eds. (2013). Research Methods in Critical Security Studies: An Introduction. Routledge, London and New York, 256 pp., \$150.00 hardcover (ISBN-13 978-0415-53539-7), \$51.95 paperback (ISBN-13 978-0-415-53540-3).

Jacob L. Stump and Priya Dixit. (2013). Critical Terrorism Studies: An Introduction to Research Methods. Routledge, London and New York, 208 pp., \$145.00 hardcover (ISBN-13 978-1-41562046-8), \$46.95 paperback (ISBN-13 978-0-415-62047-5).

Claudia Aradau, Jef Huysmans, Andrew Neal, and Nadine Voelkner, eds. (2014). Critical Security Methods: New Frameworks for Analysis. Routledge, London and New York, 230 pp., \$150.00 hardcover (ISBN-13 978-0-415-71294-1), \$44.95 paperback (ISBN-13 978-0-41571295-8).

"There is a point at which methods devour themselves" (Fanon 1952, 12).

Almost 20 years since the publication of Krause and Williams's edited volume Critical Security Studies: Concepts and Cases (1997), critical security studies (CSS) has reached a moment in which critiques of more traditional or mainstream modes of studying the politics of war, security, and violence are supplemented by a great deal of explicit attention to their methods and methodologies for doing so. The last few years have witnessed a sudden proliferation of textbooks on methods for critical security studies that have attempted to chart the field and provide guidance for students or newcomers on methods for conducting research consistent with its values and goals. The four volumes discussed in this review essay follow on the heels of numerous other textbooks that attempt to map the terrain of security studies, such as Hansen and Buzan (2009), Peoples and Vaughan-Williams's edited compilation of key and illustrative works (2010), Jarvis and Holland (2014), and the second edition of Karin Fierke's Critical Approaches to International Security (2015 [2007]). In recent years, the establishment of several journals, including Critical Security Studies and particularly Security Dialogue, as well as Journal of Global Security Studies (an ISA journal) and European Journal of International Security (a BISA journal), that are dedicated to pluralistic studies of security have also suggested the popularity and continued innovation of diverse strands of scholarship that can be grouped as "critical security studies." Furthermore, the selection of "Methods, Methodologies, and Innovation" to frame the 2014 Millennium conference and subsequent special issue also suggests a great deal of both interest and tension around the question of 
method and methodology for critical, interpretative, and pluralistic scholars, including the question of whether or not issues of "method" should be central to disciplinary debates at all.

Formalized discussions about methods might indicate a certain maturity of the field, but these discussions do not happen outside particular political and economic contexts. The question of whether "methods textbooks" are emblematic of the disciplining of critical approaches to IR is not a question that can be ignored when much of IR is taken up with questions of the tyranny of (certain types of) methods and methodologies, particularly those associated with neo-positivism. Any scholar identifying as "critical" might have good reason to be suspicious of anything resembling a "textbook" or "methods primer" for critical security studies as this could be taken as an emulation of the mainstream and its legitimation of certain methodologies as exclusively legitimate forms of knowledge. Likewise, proponents of various formerly marginal, now relatively well-established, critical theories of security could see such texts as tools of disciplinary gatekeeping. A critical scholar might even be apprehensive about the prospects of depoliticizing what it means to "do IR" by the setting forth of guidelines to be applied in order to create legitimate knowledge. Any attempt at thinking about method and methodology risks either intentional or unintentional agenda setting or disciplinary policing, as "methodology" is a key practice of legitimizing knowledge in the academy. Nonetheless, the texts reviewed here grapple to a greater or lesser degree with the question of whether methodological rigor can be pursued without losing the political impetus behind critical security studies. The neoliberal pressures that make academic labor increasingly precarious and subject to quantifiable metrics of assessment that are used to distribute resources as such as the Research Excellence Framework in the UK are themselves forms of "insecurity." Neoliberalism's everyday logics of governance via insecurity operate in parallel to the exceptional and militaristic practices of "security" that critical security scholars have critiqued for decades. Likewise, the emphasis on ascending university league tables and competitive department rankings often brings with it calls for the emulation of the quantitative and/or neo-positivist methodological training associated with many top-ranked departments in the United States. Given this insecurity for the training and career-building prospects of scholars, the ability to defend one's less-than-orthodox methodological approach in publications, grant proposals, and course design with ample citations is a matter of disciplinary survival, and, as Aradau et al. (2014) claim, part and parcel of the academic habitus. As such, it will not do to dismiss any such attempts at "speaking methods" as naïve and/or selfserving attempts at disciplinary respectability. Critical scholarship must both operate in these environments and be able to critique the conditions of knowledge production in which it is embedded.

For years, Lene Hansen's Security as Practice: Discourse Analysis and the Bosnian War (2006) served as the exemplary book-length work that could guide scholars, particularly graduate students, in how to conceptualize a research project in critical security studies. For all its theoretical sophistication, methodological specificity, and empirical elaboration, Hansen's work is primarily useful for those interested in discourse analysis, particularly in relation to identity and foreign policy. These more recent texts provide less of a detailed, step-by-step guide than Hansen's work, and none are focused solely on particular methods such as case studies, interviews, or discourse analysis, though all of these are discussed. Rather, what unites them is the attempt to provide an introduction and discussion of a broad range of methodological perspectives grouped under the term "critical," and an attempt to think through what possibilities exist for engaging with methodology from the perspective of critique.

The four works under consideration here all attempt and largely succeed in providing both guidance and justification for certain methods and interpretive 
stances as well as openings for rethinking what method and methodology might mean in relation to the ongoing question of what it means to be "critical." Texts on methods may have an inherently conservative posture, as they serve to initiate beginning researchers into established modes of conducting research, but by and large these works do this while challenging the boundaries of what constitutes "methodology."

\section{Critical Terrorism Studies: An Introduction to Research Methods (2013)}

Critical Terrorism Studies: An Introduction to Research Methods, by Jacob Stump and Priya Dixit, is perhaps the most self-consciously "performative" of the works under review here, in the sense that it strives not only to provide guidance on methods and methodological issues to scholars seeking to conduct research in the field, but also to establish critical terrorism studies as a separate and legitimate field of study. Like all of the books reviewed here, Stump and Dixit consider a diverse range of critical approaches and methodologies, such as postcolonialism and feminism, ethnography, discourse analysis, and social network analysis, as relevant to methodological questions in critical work. Stump and Dixit both analyze the methods and methodologies of existing work in critical terrorism studies, such as Richard Jackson (2005), as a guide for future researchers and suggest openings for future work in the field.

The text spends a fair amount of space addressing disciplinary debates about critical terrorism studies. As such, it is not surprising that what it means to be "critical" is understood primarily in epistemological rather than political terms. While noting that critical approaches can be aligned with the Frankfurt School's emphasis on emancipation for "unfree" groups $(2013,5)$, the "critical" in "critical terrorism studies" as understood by its various contributors and thus included by Stump and Dixit can have broader meaning depending on different theoretical influences. The common denominator is "to interrogate the commonsense assumptions that inform our analysis of security issues more broadly and terrorism in particular" $(2013,5)$, a view that does not take a particular political stance on what it means to situate oneself as a critical scholar. Stump and Dixit emphasize constitution rather than causation, or "how" versus "why" questions as well as questions of identity. While arguing for the necessity of the field of critical terrorism studies, the authors use work that they have identified as belonging to this field as the basis about how research should be designed and methods practiced, with references to classic texts on particular methods such as Foucault's work on genealogy.

Part 2 of Critical Terrorism Studies explicitly takes up the question of methods, from research designs based in the Frankfurt school (chapter 4) and feminist and postcolonial theory (chapter 5) to chapters with advice on how to carry out research. In each of these chapters, theories and methods are introduced via discussions of existing work in critical terrorism studies, sometimes through charts of different research questions and data analyzed. These chapters also make suggestions about research design and flag practical problems for the novice researcher, such as gaining acceptance into communities and personal safety when researching groups that have been identified as terrorist, as well as discussing ethical concerns such as the safety of study participants. This book would be most useful to beginning researchers such as master's or PhD students with a pre-existing interest in critical terrorism studies.

I would have liked Stump and Dixit to do more to justify critical terrorism studies as a unique field of inquiry apart from critical security studies, critical war studies, or critical international relations more generally. While they cite different arguments about whether critical terrorism studies should be a separate field, early in the book, Stump and Dixit overwhelmingly frame critical terrorism 
studies in terms of the discipline of International Relations both in terms of its development within existing IR debates (chapter 1) as well as in reference to concepts and methods developed in critical IR more generally, such as the use of "emancipation," "identity," and so forth, while simultaneously calling for critical terrorism studies to emulate critical IR methods such as Hansen's approach to discourse analysis (2006). For example, they introduce the (somewhat awkward) term "terroristization" as analogous to "securitization" as a process of the social construction/speech-act creation of "terrorists" (2013, 23). Although Stump and Dixit include brief descriptions of critical approaches to studying terrorism from other disciplines, the overall focus on the discipline of IR and the lack of broader social, political, and economic rationale for the autonomy of "critical terrorism studies" aside from the rise of a mainstream "terrorism studies" seems to undermine their position. Some cases, such as the discussion of interviews/ethnographies of "terrorist" groups, run the risk of reifying state discourses of terrorism and terrorist groups as a unique form of political violence (thus legitimizing particular policies toward such activities and groups associated with them). Overall, while this volume constitutes an important effort at advancing the emerging critical terrorism studies agenda, its immersion in disciplinary debates means that it misses an opportunity to think about what doing "critical" work might mean for terrorism studies in a way that is more robustly political and less defined in terms of a post-positivist epistemological standpoint.

\section{Critical Approaches to Security: An Introduction to Theories and Methods (2013)}

Critical Approaches to Security: An Introduction to Theories and Methods, edited by Laura J. Shepherd, is clearer about the explicitly political nature of scholarship in security studies. In her introduction, Shepherd stresses that this book is about methodology, which she emphasizes is different from both theory and method. Methodology is conceived as a "theory about methods" $(2013,1)$, while Shepherd also notes that discussions of the politics of knowledge span the book's sections of both theory and method. The "critical" in "critical security studies" as defined by Shepherd is about the implication of theory in everyday life and the need to question embedded power structures, including practices of research and criticality itself $(2013,3-5)$.

The first half of the volume is dedicated to theory, while the second half addresses a wide variety of methods, understood as "techniques for the collection and analysis of data" $(2013,6)$. The "theory" chapters cover various schools of critical security studies, including feminist security studies, green security, "securitization," postcolonial security studies, and more. The demarcation of these as distinct schools might be critiqued, but it is no doubt useful for beginning students, and furthermore the problems with such demarcations are noted by several contributors, including Soumita Basu and João Nunes in their chapter on the "Welsh" school or "Security as Emancipation." The contributions in this volume are, with few exceptions, notably lucid and accessible without sacrificing sophistication. All of the contributions to Shepherd's volume first provide an overview of the particular theory or method addressed but helpfully move on to illustrate the theory or method using cases or examples from the contributor's own expertise, such as rape in war, human security, the Bhopal industrial accident, trafficking, or sanctions. By focusing on how contributors conducted their research, the emphasis in the volume is on bridging the gap between theory and practice. In a gesture of constructive engagement, the authors discuss their limitations to particular theories or methods, along with various pitfalls to avoid and ethical questions to consider. Each contribution also contains discussion questions and links to the companion website, and is accompanied by helpful boxes, charts, and similar elements to explain or illustrate particular ideas. Shepherd's volume stresses that 
different methods can be put to use for different theoretical/political purposes; notably, a chapter by Laura Sjoberg and Jeffrey Horowitz argues that quantitative data collection is not necessarily opposed to critical theory and argues for the possibility of using game theoretic models as part of multi-method approaches for critical projects.

A key theme linking these works is reflexivity, which is not surprising, but in these discussions of methods, "reflexivity" becomes more than an abstract epistemological concept through its lively illustration from contributors. Cai Wilkinson's chapter on ethnography (2013, 129-45), for example, contains an extended discussion of reflexivity and positionality that does not only define these terms and situate them in the theoretical literature, but also provides a set of questions meant to spur the practice of being reflexive about one's positionality in the course of research. Wilkinson insists that "reflexivity is not just something that can be bolted on to our research as a discrete issue to consider if it is to be able to interrogate the normative assumptions inherent in debates about 'security' and the discipline of IR more widely" $(2013,132)$, but rather that reflexivity has to be part of research design and ethics from the start. Ruth Blakeley's chapter also stands out for providing advice for some of the very real questions that students struggle with, such as gaining the trust of elite actors one is interviewing while remaining true to the critical ethos of reflexivity. In conversational tones, Blakeley describes her research processes with valuable insights about mistakes made and lessons learned, and useful pointers about handling sensitive information.

Penny Griffin's chapter on "deconstruction as anti-method" (which actually includes a "how to" outline for deconstruction) is perhaps the site where the tensions between "methodology" and "criticality" become most apparent. Highlighting Derrida's claim that reading is itself an act of writing, and thus there is no separation of the text and the exterior application of method $(2013,209)$, Griffin describes deconstruction as an "anti-method" because of the way the text itself contains its own undoing and provides insights into the debates around and limitations of deconstructive approaches before proceeding to offer a deconstructive reading of an image and a text. Griffin's chapter is a telling example of how it is possible simultaneously to question central assumptions of what it means to think about methods while using perspectives from critical theory to guide research nonetheless. Overall, Critical Approaches to Security provides a balance between accessibility and theoretical rigor, sophistication, and practicality that makes it an excellent resource for advanced undergraduates, master's, and PhD students.

\section{Research Methods in Critical Security Studies: An Introduction (2013)}

Research Methods in Critical Security Studies, edited by Mark B. Salter and Can E. Mutlu, is a tour through diverse approaches to research in CSS that is notable for its emphasis on emerging critical scholarship, such as works falling under the headings of "the corporeal turn," the "practice turn," and the "material turn," as well as the relatively more familiar territory of discourse analysis and ethnography. The focus is less on "methods" per se than on research design. As such, the text is not as invested as the Shepherd or Stump/Dixit volumes in explication of theoretical stances (although in-text boxes provide lucid introductions to major thinkers and concepts), but in connecting theories to methods and methodologies through "clean" research design. The Salter/Mutlu volume is perhaps the most explicit of this set of works about its political project of seeking a "more fullthroated voice" $(2013,14)$ to engage with mainstream or American-style positivism, while at the same time moving the practice of doing critical research beyond the need to "reinvent ... critical inquiry in each intervention" (2013, 2). 
Criticality, as identified by Salter in his introduction, shares a series of postures: that social and political life is messy and thus demands methodological pluralism, that agency is everywhere and found in a variety of different types of actors, that causality is emergent and thus analysis is about locating conditions of possibility rather than efficient causes, and that research and writing are inherently political. The main justification for making research design explicit is the problematic nature of reducing the question of methods to theory: "[ $\mathrm{t}]$ heory alone grounds our research in a certain philosophical tradition, but it does not answer questions of clarity, coherence, and reflexivity" $(2013,13)$. Insisting that "each theory has a bespoke method" $(2013,14)$ that connects to a particular research design, Salter cautions that theory does not answer questions of clarity, coherence, and reflexivity in research design: these must be separately considered and articulated. To replace the standards of parsimony, replicability, or efficiency from more positivistoriented scholarship, Salter poses as questions, rather than rules, the challenges of sufficiency (when can data retrieval stop?), coherency (what counts as a compelling argument?), and criticality (what is a reasonable critical position?), the answers of which will need to be justified based on the theoretical tradition and the research project as a whole, with the researcher being explicit about his or her choices $(2013,19)$.

Salter advocates "clean" research design, by which he identifies clarity, fit, and reflexivity as core principles, each related to his identification of a critical posture $(2013,15)$. Clarity means that the case study or studies connect to key concepts and set out the relationship to study, that there is a connection to the literature, and that the research process is flexible enough to allow for success or failure. "Fit" refers to certain methods for certain research questions, stemming from an engagement with theory as well as empirical reality and noting that multiple methods may be appropriate for different theoretical perspectives $(2013,17)$. Reflexive analysis incorporates the individual researcher's relationship to his or her sites of study and in the broader institutional context in which he or she operates and the kinds of research that are encouraged. These general principles are focused enough to give beginning researchers pertinent questions to consider and articulate when transitioning from students who have read a lot of theory to those starting to design their own research projects, while at the same time being far from overly formulaic and prescriptive. The Salter/Mutlu book attempts a balance between promoting "clean" research design and its investments in providing a wide variety of different possibilities for what this might look like.

Research Methods in Critical Security Studies begins with a section on research design followed by an opening set of chapters that expand upon issues of what it means to use a critical posture to inform one's research. The rest of the book is organized around a series of "turns" in IR theory: the ethnographic turn, the practice turn, the discursive turn, the corporeal turn, and the material turn. Salter and/or Mutlu open each section with an introduction that contains some of the most concrete and useful insights into the practice of connecting theoretical perspectives to a clean and coherent research design. Similar to their definition of "critical" in terms of "postures" rather than a set of propositions to which all agree with, neither the sections grouped around these so-called "turns" nor the individual chapters within each section are precisely parallel to each other or address distinct "schools," or "theories" or "methods," although they are referred to as "methodologies." The framing of these as "turns" could be critiqued for the way it narrates the development of IR theory in its implication that new developments in IR theory supplant prior work in a progressive sense. Framing these developments as turns also runs the risk of homogenizing theoretical influences and research practices within each heading, as well as drawing problematic distinctions between, say, "the practice turn" from "the corporeal turn" and each as separate 
from "the material turn," neglecting some of the overlapping influences and concerns of each.

However, given the attention to outlining key differences in theoretical approaches (Actor-Network Theory in comparison to Jane Bennett's concept of "thing-power" within "the material turn," for example), as well as the diversity of voices contributing to discussions to research in each section, it might be more fair to assert that these "turns" are based more on convenience than internal coherence, especially as they may be used to guide students with a specific interest in a "turn," and steer them toward multiple modes of conducting research successfully. The section on "the corporeal turn" illustrates this approach to articulating the diversity within each proclaimed "turn": in his introductory remarks, Mutlu notes that there is no singular "method" most appropriate for conducting research according to this "posture": autoethnography, interviews, participant observation, discourse analysis, and analyzing practices are all suitable methods, depending on what theoretical concepts and framework one is working with (year, 140). After a discussion of the literatures on the concepts "corporeal," "affect" and "emotion," and "reflexivity," Mutlu sets out a series of questions that should be addressed in order to construct a research design, and analyzes three works, Elaine Scarry's The Body in Pain (1985), John Protevi's Political Affect (2009), and one of the chapters in this section, Philippe M. Frowd and Christopher C. Leite's "Affect at the Airport," as successful examples of corporeal research, articulating how the object of analysis is theorized, how data are collected, the political relations that are theorized, and the more nebulous "fit." Mutlu insists the corporeal turn includes diverse topics like affect, emotion, and the somatic, and elides (perhaps necessarily) controversies over how these terms are defined. However, the chapters that follow suggest a wide variety of possibilities for work involving corporeality-suggesting less of a decisive "turn" and more of a "family-resemblance" approach to what corporeal methodologies might entail.

The 34 chapters are brief (fewer than five pages) and conversational, drawing out complex issues of the political nature of scholarship. In form and tone, it is closer to Ackerly et al. (2006), with the authors providing personal reflections on how they did their research, than the generally more formal tone of the other works discussed here. The volume goes beyond a textbook of theories and procedures to the creation of an assemblage of overlapping, interconnected voices. Notwithstanding Salter's emphasis on "clean" research design, if a theme could be drawn out from the contributions it would echo Vicki Squire's chapter "Attuning to mess" (2013, 37-41), which draws on John Law and his collaborators' work that challenges the notion that we can presume to know what the objects of our research are or how they should be studied beforehand, which risks reducing complex phenomena and processes to overly simplified registers. This ethos is well demonstrated in this volume, that, taken as a whole, resolutely refuses to provide hard-and-fast rules to apply despite its dedication to methodological rigor: a "clean" research design need not incorporate any single method or lead to simplistic accounts of the world but must be clear in its articulation of questions, case selection, justification of its methods, and so forth. Far more than providing a summary of theories and a "how-to" guidebook for methods, this volume constitutes an important contribution toward critical security studies in its own right for its insistence that critical security studies scholars need not perform rote justifications of a critical stance vis-à-vis more positivistic standards of knowledge production while remaining attentive to the many methodological challenges and opportunities that critical scholarship entails.

While Salter's emphasis on "clean" research design could be critiqued, as it is implicitly by Aradau et al. (discussed below), Salter and Mutlu's emphasis on clarity in research design, appropriateness of methods, and reflexivity combined with 
the multitude of voices (predominantly of relatively junior scholars) included in this volume creates an overall impact that is less about prescriptive statements regarding research design and disqualifying certain approaches or "postures" than it is about opening up spaces for new "postures" toward research to flourish in critical security studies and IR more generally. The personal reflection of how both beginning and more established researchers have actually conducted their research will be extremely helpful for students and researchers bewildered with the question of what one actually does and how it is justified, as well as revealing the messiness and often unpredictable nature of doing critical research.

\section{Critical Security Methods: New Frameworks for Analysis (2014)}

While of this group of books the Shepherd and Salter/Mutlu editions are perhaps the most useful guidebooks for graduate students and upper-level undergraduates about to embark on independent research, Critical Security Methods: New Frameworks for Analysis, edited by Claudia Aradau, Jef Huysmans, Andrew Neal, and Nadine Voelkner (henceforth Aradau et al.), moves beyond textbook introductions and reflections on different methods in ways primarily meant to guide newer researchers to a provocative contribution on the politics of methods, methodology, and theory within critical IR more broadly. This work's primary goal is to argue for a greater appreciation of the "political life of methods" (2014, 10). Having the advantage of following and thus being able to respond to the Shepherd and Salter/ Mutlu volumes in particular, Aradau et al. take up the challenge of Aradau and Huysmans (2014) to understand methods not as "mere technique" but as explicitly performative devices and acts for enacting and rupturing social worlds. The title of this book recalls Barry Buzan, Ole Wæver, and Jaap de Wilde's Security: A New Framework for Analysis (1998), a key work in the "Copenhagen" school of security studies that argued for a wider security agenda, a bridging of positivist and postpositivist approaches, and an analysis of the process of "securitization" as a speechact. In comparison, Aradau et al. aim to widen the scope of the political in critical security studies to the performativity of methods/methodologies. In their introduction, the editors argue that "the concerns of CSS with practice and problematizations should be extended to the practice and problematizations of method itself. We ask not only what it means to treat security as practice by also what it means to treat method as practice" $(2014,6)$. In other words, Aradau et al. seek to change the conversation about methods from a question of the proper application of a research method to "what do methods do in and to the security and security studies fields where they are practiced?" $(2014,16)$.

Drawing from the sociological "practice turn," Aradau et al. note that "methods" are a key way in which "security" is practiced, and at the same time, "critical" work is part of the academic habitus, rather than a strictly position of critique. In this, Aradau et al.'s volume moves the debate about methodology and IR decisively away from the "third debate" (or "fourth debate," depending on how one counts) of decades ago, which established a crucial dividing line between positivist and post-positivist work on the grounds of whether knowledge production and the subjectivity of researchers can be separated from questions of politics. Due to both the current academic environment as well as contemporary practices of security, methods that have been considered "critical," or at least non-positivist, cannot themselves be assumed to be politically progressive, innocent, or unproblematic. Critical security methods such as ethnographies and social network analysis have been used for the exercise of power in colonization and counterinsurgency practices, while statistical methods have been used to combat dominant power relations, such as in challenging inequalities caused by neoliberal economic policies $(2014,11)$. Aradau et al. call for a renewed analysis of the "political life of methods" and to move the agenda of critical security studies from security as an object 
of research to a more thoroughgoing challenge to "any rigid separation between different methods, the different users of methods, and the different uses of methods" $(2014,10)$.

In so doing, Aradau et al. share a general ethos with the works discussed above to further methodological reflection from a perspective critical of the power relations present within practices of knowledge production. However, Aradau et al. go further than the works above by rejecting the idea of methodology as metatheoretical reflection or as the bridge between theory and practice for a notion of "assemblage" or "bricolage" that brings together different theories, methods, and data attuned to the complexities of the world. In addition to critiquing the familiar language of rigor, detachment, and consistency, Aradau et al. also target what they term a "rationalist" perspective on methods. The term "rationalist" is meant to refer the idea that methods are a particular choice of analytical tools that follow rationally from a particular theory to a coherent set of procedures and techniques, as in a "cascade" from theory to methodology to method along the lines of Jackson's (2011) treatise on the "philosophical wagers" of different epistemological views and research aims of different forms of science, as well as in Shepherd's edited volume discussed above. ${ }^{1}$ The choice of the term "rationalist" here aligns even some work in critical methods and methodologies with more mainstream "rational choice" methods. Regardless of the merits of this critique in regard to individual texts or contributors, this is a useful starting point for a deeper reassessment of what it means to do critical security studies at this particular moment in the discipline and how it relates to broader political and economic developments.

The problem with the cascading approach to theory, methodology, and methods, Aradau et al. argue, is that it addresses the meaning, purpose, and practice of scholarship in advance of the scholar's use of methods in their encounter with the empirical world, effecting a separation between the two. Method, as Aradau et al. understand it, is not a tool to bridge theory and empirics, or representation and reality. Nor is it a mechanism to sustain the credibility of knowledge produced within the academy or elsewhere (cf. Salter/Mutlu in particular). Rather, method "questions how to problematize security practices and processes, how to interfere and intervene in security knowledge by analysing the processes and conditions through which insecurities are made politically significant" $(2014,9)$. The Aradau et al. volume works to sharpen the "critical" aspect of critical security methods by pushing the envelope toward the creation of new "methodological assemblages" that are more concerned with the creative deployment of concepts, data, and methods in experimental forms of knowledge production that are more interested in generating new insights than applying prescribed techniques. Critical Security Methods: New Frameworks of Analysis embodies the experimental ethos itself with its four-member editorial collective and every chapter authored by multiple scholars.

Unlike many methods texts, this book is not designed to be consulted for the chapters that one has already decided are of interest; the book is organized in terms of "methodological problematizations" of insecurity rather than a list of methods, theories, or "turns." To a greater extent than the other works under consideration in this essay, the chapters deploy the analytical framework advanced

\footnotetext{
${ }^{1}$ Aradau et al.'s "experimental" approach to methods can be compared to J. Samuel Barkin and Laura Sjoberg's recent Millennium piece (2015) that also questions the pathway from ontology to epistemology to methodology to method in International Relations, arguing that statistical modeling and behavioral modeling, for example, can productively add to the arsenal of methods that critical work might use. Both question a simplistic and taken-forgranted movement from "theory" to "methodology" and "methods," and both take Hayward Alker's (1996) work in particular as inspiration for this. However, Aradau et al. are concerned to avoid "methods" per se for "methodological problematizations" of insecurity $(2014,10)$ and experimentation with different methods, taking seriously the political implications of different techniques for security problematizations.
} 
in the introduction to develop different methodological assemblages: mapping, visuality, discourse and materiality, proximity and distance, genealogy, and collaboration. These chapters thematically overlap to offer different methodological experimentations that combine sets of concepts, orientations, empirical sites, and modes of organizing methodological practice that carry the critical sensibilities of critical security studies into methodological discussion. For example, rather than separate chapters on "discourse," "materiality," and "corporeality," a chapter entitled "Discourse/Materiality" ${ }^{2}$ refuses to divide these concepts and centers on a discussion of three different ways to analyze the co-constitution of materiality and discourse: dispositifs, performativity, and agency, all of which can be considered an operationalization of the relationality between materiality and discourse. Through a discussion of several "dangerous objects," such as certain drugs, and the work of Foucault, Butler, Barad, Bennett, Deleuze, and others, the authors explore how contingent combinations of discourses/materiality can come to matter in security practices, and how they might be researched.

Another example of what Aradau et al. mean by "methodological assemblage" is the chapter on "mapping" by Victoria Loughlan, Christian Olsson, and Peer Schouten, which is inspired by the "practice turn" to analyze the practice of mapping by both security practitioners and security scholars. "Mapping" does not (yet) name an existing research method or "theory" of International Relations, but this chapter, like others, explores the possibility for an amalgamation of different research questions, theories, topics of concern, and vocabularies to provide new insights into the contemporary milieu of security. This chapter frames the question of "mapping" in terms of how a phenomenon is materially represented, what effects this "map" has in terms of its productive capacity to rearrange human bodies and other elements and processes, as well as the circulation and various uses of the maps. The authors then describe and compare Bourdieu and Latourinspired approaches to mapping, explaining the different concepts and approaches to the analysis of mapping practices suggested by each theorist. They trace tensions as well as lines of overlap, with the overall goal being to set out the possibility of a new matrix of research topics in security studies.

These speculative "methodological assemblages" are a refreshing counter to what many in the discipline have noted is a "camp" structure of certain "schools" interacting only with their own members. This "assemblage" structure avoids reifying certain schools (such as Welsh, Parisian, Copenhagen, etc.), yet it is less successful than Aradau and Huysmans (2014) at making the diverse and multi-vocal feminist contributions to theorizing methods and methodology a central part of critical thought (see also Sylvester 2007). The goal for Aradau et al. is not a comprehensive and exclusive charting of the terrain of methods and critical security studies as much as it is a reconfiguration of the way the field as a whole is understood and practiced. The organization of the text reinforces the editors' agenda that critical security studies engage in practices of "rupturing not simply existing truths but habitual and institutionalized uses of methods that reproduce dominant political practices" $(2014,14)$. It does not seek to advance discussions on the proper methodological approaches for pre-existing schools of thought or "turns" within IR theory but through its own collective endeavors, to open up new alliances and re-envision what paths critical inquiry might take in the future.

\section{Conclusion}

Overall, the volumes under consideration represent a moment in which critical security studies as a disciplinary subfield is simultaneously attempting to solidify

\footnotetext{
${ }^{2}$ Claudia Aradau, Martin Coward, Eva Hershinger, Owen D. Thomas, and Nadine Voelkner authored this chapter.
} 
its presence with its own internal standards for research design, methodologies, and methods within International Relations while at the same time retaining and strengthening its commitments toward criticality that require the process of research itself to be subject to an open-ended critique for its own complicity in ongoing relations of domination. "Critical" approaches to the study of terrorism and security can no longer be considered, if they ever could, to be working outside power relations, either within or outside the academy, even if they do not usually enjoy the same status as more quantitative or positivist scholarship. While more focused attention on the process of research is perhaps a political and economic necessity at this moment given the increasing precarious conditions of academic labor and knowledge production as well as being justified given the diversity of approaches to research that characterize self-identified "critical security scholars," we should also strive to remember Fanon's statement that begins this piece: "there is a point at which methods devour themselves" $(1952,12)$. Attempts at articulating methods and methodologies for critical security studies are perhaps bound to be inadequate in a certain sense, caught as they are between an articulation of pathways to trustworthy knowledge production, even based on internal standards, and the practice of critique in a world in which the terms of security/ insecurity are changing and perhaps have no essential logic of their own (Browning and McDonald 2013). The diversity of methodological perspectives on display in these recent works suggests the possibility (but not inevitability) of a more rigorous critique of the practice of critical research in increasingly insecure academic environments. Methodological rigor for critical theorists, at this point, involves less a defense of one's own right to exist within International Relations and more a struggle to define what it is critical researchers actually $d o$ in terms that can help such work survive in academic environments defined by increasing competition for secure jobs and resources. At the same time, as these works demonstrate, being "rigorous" as a critical scholar also means being attentive to the politics of articulating methodology, lest the imperatives to specify one's methods quash some part of the ability to think critically about the practices of security and insecurity inside and outside the academy, including methods themselves.

\section{Acknowledgements}

Thanks to the editors and to the anonymous reviewers for their feedback and helpful suggestions regarding this work.

\section{References}

Ackerly, Brooke, Stern Maria, and True Jacqui, eds. 2006. Feminist Methodologies for International Relations. Cambridge: Cambridge University Press.

Alker, Hayward. 1996. Rediscoveries and Reformulations: Humanistic Methodologies for International Studies. Cambridge: Cambridge University Press.

Aradau, Claudia, and Huysmans Jef. 2014. "Critical Methods in International Relations: The Politics of Techniques, Devices and Acts.” European Journal of International Relations 20 (3): 596-619.

Aradau, Claudia, Jef Huysmans, Andrew Neal, and Nadine Voelkner, eds. 2014. Critical Security Methods: New Frameworks for Analysis. London and New York: Routledge.

Barkin, J. Samuel, and Laura Sjoberg. 2015. "Calculating Critique: Thinking Outside the Methods Matching Game.” Millennium: Journal of International Studies 43 (3): 852-71.

Browning, Christopher S., and Matt McDonald. 2013. "The Future of Critical Security Studies: Ethics and the Politics of Security." European Journal of International Relations 19 (2): 235-55.

Buzan, Barry, Ole Wever, and JaAp de Wilde. 1998. Security: A New Framework for Analysis. London and Boulder: Lynne Rienner.

Fanon, Franz. 1952. Black Skin, White Masks. Translated by Charles Lam Markmann. New York: Grove Press.

Fierke, Karin M. 2015 [2007]. Critical Approaches to International Security, 2nd ed. Malden, MA: Polity Press. 
Hansen, Lene. 2006. Security as Practice: Discourse Analysis and the Bosnian War. London and New York: Routledge.

Hansen, Lene, and Barry Buzan. 2009. The Evolution of International Security Studies. Cambridge: Cambridge University Press.

Jackson, Patrick Thaddeus. 2011. The Conduct of Inquiry in International Relations: Philosophy of Science and Its Implications for the Study of World Politics. New York and London: Routledge.

JACKSON, RichaRd. 2005. Writing the War on Terrorism: Language, Politics and Counterterrorism. Manchester: Manchester University Press.

Jarvis, Lee, and Jack Holland 2014. Security: A Critical Introduction. London: Palgrave Macmillan.

Krause, Keith, and Michael C. Williams, eds. 1997. Critical Security Studies: Concepts and Cases. New York: Routledge.

Peoples, Columba, and Nick Vaughan-Williams. 2010. Critical Security Studies: An Introduction. Abingdon and New York: Routledge.

Protevi, John. 2009. Political Affect: Connecting the Social and the Somatic. Minneapolis: University of Minnesota Press.

Salter, Mark B., and Can E. Mutlu, eds. 2013. Research Methods in Critical Security Studies: An Introduction. London and New York: Routledge.

SCARry, Elaine. 1985. The Body in Pain: The Making and Unmaking of the World. New York and Oxford: Oxford University Press.

Shepherd, Laura J., ed. 2013. Critical Approaches to Security: An Introduction to Theories and Methods. London and New York: Routledge.

Stump, Jacob L., and Priya Dixit. 2013. Critical Terrorism Studies: An Introduction to Research Methods. London and New York: Routledge.

Sylvester, Christine. 2007. “Anatomy of a Footnote.” Security Dialogue 38 (4): 547-58.

Wilkinson, Cai. 2013. "Ethnographic Methods." In Critical Approaches to Security: An Introduction to Theories and Methods, edited by Laura J. Shepherd, 129-45. London and New York: Routledge. 